\title{
The current understanding of knowledge management concepts: A critical review
}

\author{
Shahram Yazdani ${ }^{1}$, Snor Bayazidi*1 ${ }^{(\mathbb{D}}$, Amir Ali Mafi ${ }^{2}$ \\ Received: 7 May 2019 \\ Published: 28 Sep 2020
}

Abstract

Background: Higher education institutions include experts who are knowledgeable. Knowledge management facilitates institutions to enhance the capacity to collect information and knowledge and apply it to problem-solving and decision making. Through the review of related studies, we observed that there are multiple concepts and terms in the field of knowledge management. Thus, the complexity and variety of these concepts and definitions must be clarified. Considering the importance of clarifying these concepts for utilization by users, this study aimed to examine the concepts related to this filed.

Methods: The methodology used in this study was based on the Carnwell and Daly's critical review method. An extensive search was carried out on various databases and libraries. A critical and profound review was carried out on selected articles. Many wandering concepts were found. Identified concepts were classified into seven categories based on conceptual proximity. Existing definitions and evidence in relation to extracted concepts were criticized and synthesized. The definitional attributes for them were identified and a conceptual identity card was provided for each of the concepts.

Results: Thirty-seven concepts with the most relevance to the field of knowledge management were extracted. There was no clear boundary among them, and they wandered. To avoid more confusion, concepts were classified according to semantic relation. Eight categories were created; each category consisted of a mother concept and several other concepts with similarity and proximity to the meaning of the original concept. Their attributes have been identified, and finally, each of them was presented in the form of a conceptual identity card.

Conclusion: Through critically reviewing the literature in this field, we were able to identify the concepts and realize their attributes. In this way, we came to a new interpretation of the concepts. At the end of the study, we concluded that some of the concepts have not been properly defined and are not properly located in the knowledge management field; also their application is uncertain.

Keywords: Knowledge management, Knowledge translation, Knowledge transfer, Knowledge generation

Conflicts of Interest: None declared.

Funding: None

*This work has been published under CC BY-NC-SA 1.0 license.

Copyright $\odot$ Iran University of Medical Sciences

Cite this article as: Yazdani Sh, Bayazidi S, Mafi AA. The current understanding of knowledge management concepts: A critical review. Med J Islam Repub Iran. 2020 (28 p);34:127. https://doi.org/10.47176/mjiri.34.127

\section{Introduction}

The organization in the age of knowledge is an organiza-

Corresponding author: Dr Snor Bayazidi, snoorbayazidi@sbmu.ac.ir

1. Virtual school of Medical Education and Management, Shahid Beheshti University of Medical Sciences, Tehran, Iran

Anesthesiology Research Center, Shahid Beheshti University of Medical Sciences, Tehran, Iran tion that is based on the best available knowledge and in-

\section{$\uparrow$ What is "already known" in this topic:}

There are numerous and complex concepts in the field of knowledge management that have not been clarified, and most of them are used incorrectly. For example, in many studies, the concept of knowledge management and knowledge translation are used interchangeably, and there is no distinct boundary among concepts.

\section{$\rightarrow$ What this article adds:}

The identified concepts were wandering. To avoid more confusion, concepts were classified according to semantic relation. Eight categories were created, including a sentinel concept and several other neighbor concepts. Their attributes have been identified, and finally, each of them was presented in the form of a conceptual identity card. 
formation. To succeed in today's challenging organizational environment, organizations need to learn from past mistakes rather than repeating those mistakes. This process occurs through knowledge management $(1,2)$. Knowledge management $(\mathrm{KM})$ is important, especially for organizations that their successes depend on the production, use, and integration of knowledge by professionals and employees. Higher education institutions are made up of experts who are knowledgeable. KM is a new field in the academic environment, and many universities are actively involved in related activities in this field (3). Conferences and seminars are taking place at the national and international levels in this regard. In the field of education, due to the need to explore the power and intellectual capital available to share experiences, this area has been very much considered (4). All knowledge production organizations such as research, development centers and higher education institutions from colleges to universities are looking for new concepts in their favorite subject. They also help create knowledge through various programs, considered as "knowledge houses" (5). So, the knowledge of the professors flows to the students and new knowledge is produced. Information is created in various forms and sources such as books, articles, dissertations, reports, and more. Knowledge management helps these institutions to enhance the capacity to collect information and knowledge and apply it to problemsolving and decision making (6). Therefore, evidence shows that any academic institution is associated with knowledge. In these institutions, the information and knowledge gained in the scientific community's core area should be disseminated for further growth (5). But, there are challenges in this direction. Studies have demonstrated that knowledge created in educational institutions is not properly stored and obtained. Most of the time, knowledge created in that system remains unknown and is considered as gray literature (6). The academic environment is considered as the knowledge houses, but if the generated knowledge in that organization is not properly organized, it will minimize its usefulness and leads to repeat activities (7). Despite the importance of knowledge management for educational systems, there is still no awareness about its development by academics. There is a need to create a culture of sharing knowledge among professors, staff and students who are still afraid of losing their knowledge through exchange and dissemination (8). The use of information communication technology and the development of advanced skills in the training of professions for the purpose of participation, communication, acquisition, recording and dissemination of knowledge are used very poorly in universities. Therefore, they need to adopt a policy in this regard (7). New educational systems are market-oriented and are becoming entrepreneurs. They should be accountable to the academic governance system. Therefore, educational institutions and academics faced with global pressures, research, and interdisciplinary subjects. In the complexity of such as global education market, there is a need for a motivating environment (6).

We mentioned the importance of knowledge management in the educational system, as well as the existence of challenges in this direction, but although much research has been done in this regard, knowledge workers, those who are willing to do research or scientific activity in this area face difficulties. The main reason for this problem is that there are numerous and complex concepts in this area that have not been clarified, and most of them are used incorrectly. For example, in many studies and even by academics, the concept of knowledge management and knowledge translation are used interchangeably, and there is no distinct boundary among concepts. On the other hand, despite the multiplicity of concepts in this field, the research that has examined all of these concepts together has not been found. Considering the importance of clarifying these concepts for utilization by users, the first step in this direction is to identify and clarify concepts associated with knowledge management. Therefore, in this study, we intend to examine the concepts and definitions related to them through a critical review method, accordingly identify their attributes, and based on the identified attributes, concepts become clear.

The result of this study can help managers, policymakers, professors, students, and researchers who after us, intend to carry out research related to the field of knowledge management.

\section{Methods}

Our methodology was based on the critical review of the literature introduced by Carnwell and Daly. The following five steps were performed; 1- detremination the scope of the review, 2-identification relevant information resources, 3-literature review, 4-writing the review,5- application of the review results in the study (9).

The review scoop was theoretical research published in the research journals. An extensive search was carried out on various databases (google scholar, PubMed, Embase, Elsevier, Scopus, Iran Medex, SID, and online libraries and dictionaries). The main keywords in the search were: knowledge management concepts, knowledge management stages, knowledge management implementation, knowledge management in higher education, and knowledge management in medical education. As a result, numerous articles were found. To restrict the search results, we set the inclusion criteria and exclusion criteria. Inclusion criteria were the studies and books related to knowledge management concepts without time limitation. Non-academic research was the exclusion criteria. The articles were examined superficially. Then the primary screening was done on the titles. So, a summary of the articles was studied and those articles that were most closely related to the concepts of knowledge management were selected to study the full text. Priority in reading was based on their relevance to study objectives and literature with more conceptual richness. A critical review was carried on publications with the purpose of clarifying the boundary among concepts. Thirty-seven concepts that were involved in the KM process were extracted. Since there were many wandering concepts in this path, in order to avoid confusion, they were examined based on semantic proximity in separate categories. Each category included a mother concept and other related concepts to it. Then by synthesizing existing definitions and evidence about each of the concepts, we tried to identify the characteristics on which they 
are defined. Ultimately each of the concepts was presented in the new classification based on these characteristics.

\section{Results}

There were many wandering concepts in the field of knowledge management, in order to avoid bewilderment; concepts were examined based on semantic proximity in separate categories. Each category included a mother concept with related concepts to it. By critique and comparing the definitions and evidence about each of the concepts, their attributes were identified. Finally, based on these features, a conceptual identity card for each concept was presented. Our result presented in nine categories: knowledge Generation (knowledge acquisition, knowledge selection, knowledge building, knowledge creation, knowledge capture), Knowledge processing( knowledge synthesis, knowledge integration, knowledge refinement, knowledge tailoring, knowledge customization)knowledge storage (knowledge assimilation, knowledge package, knowledge documentation, knowledge indexing), Knowledge transfer( knowledge sharing, knowledge exchange, knowledge dissemination, knowledge publication), Knowledge capitalization( knowledge commercialization, knowledge valorization), Knowledge brokering, Knowledge utilization(, knowledge adoption, knowledge adaptation, knowledge reuse), Knowledge translation, and Knowledge management.

In the following, the conceptual identity of each of the concepts, which includes the specific features about that concept, is introduced.

Knowledge Generation: Knowledge acquisition, knowledge capture, knowledge selection, knowledge creation, knowledge building.

\section{Knowledge acquisition attributes}

Purpose: The purpose of knowledge acquisition is to enhance the organizations' competitive edge through increasing an organization's operational knowledge base (10).

Source of obtaining knowledge: The source of obtaining knowledge is internal and external sources (10).

Type of acquired Knowledge: Type of acquired knowledge can be either tacit or explicit (10).

Activities: Activities related to knowledge acquisition are identification of knowledge, obtaining the identified knowledge, transferring the knowledge for immediately using or internalization (11).

Key point: Knowledge acquired can either be tacit or explicit but must add value to the organization (10).

\section{Knowledge selection attributes}

Purpose: The purpose of knowledge selection is Identification the knowledge according to organizational needs in internal sources, Provide knowledge at the appropriate place and by the appropriate form (12).

Source of obtaining knowledge: Knowledge is obtained from internal sources (12).

Activities: Knowledge selection activities include the following: identification of knowledge from internal sources, obtaining the identified knowledge from internal sources, transfer the knowledge for immediately using or internalization (12)

Key point: Knowledge selection is the opposite point of knowledge acquisition (12).

\section{Knowledge capturing attributes}

Purpose: The purpose of knowledge capture is to maintain knowledge in order to organizational performance improvement, ensure that knowledge available is stored for future reference (13).

Form: Knowledge captured in the form of databases or manuals (13).

\section{Knowledge creation attributes}

Context: Knowledge creation occurs through the inference or discovery from knowledge sources (12).

Purpose: Creating or producing knowledge helps organizations gain a competitive advantage by providing valuable, rare, and inimitable resources (14). Utilization of complex and discontinuous events and phenomena to Confronting recognized organizational problems (15).

Activities: Knowledge selection activities include the following: control the organizational knowledge, Control the external environment, Creation knowledge from the existing basic knowledge, Transfer created knowledge for externalization or internalization (12).

Knowledge creation place: Knowledge is produced in the Research community, Professional Councils, Ministries and governmental organizational, Transfer and innovation centers, Science communities (16).

Form: Some scientists have defined knowledge creation as a process, output, and outcome $(15,17)$.

\section{Knowledge building attributes}

Context: The term knowledge building first appeared in the learning sciences literature (18).

Purpose: The purpose of knowledge creation is the creation or modification of public knowledge - knowledge that lives 'in the world' and is available to be worked on and used by other people. These pursuits should advance the current understanding of individuals within a group, at a level beyond their initial knowledge level, and should be directed towards advancing the understanding of what is known about that topic or idea (19).

Steps: Knowledge building consists of the following steps: creation, testing, and improvement of conceptual artifacts (19).

Requirements: It encompasses the foundational learning, sub-skills, and socio-cognitive dynamics pursued in other approaches, along with the additional benefit of movement along the trajectory to mature education (20).

Path: Knowledge building can be considered as deep constructivism that involves making a collective inquiry into a specific topic and coming to a deeper understanding through interactive questioning, dialogue, and continuous improvement of ideas. Ideas are thus the medium of operation in KB environments (20).

Key point: Knowledge building projects focus on understanding rather than on accomplishing tasks, and on collaboration rather than on controversy (20). 
Knowledge processing: Knowledge filtering, knowledge synthesis, knowledge integration, knowledge refinement, knowledge customization.

\section{Knowledge processing attributes}

Context: Knowledge processing is a significant factor contributing to socioeconomic sustainability (21).It is a central problem of Artificial Intelligence (22).

Purpose: The purpose of Knowledge processing is to understand the relationship among data, information and knowledge and create knowledge structures (23).

Method: The knowledge processing method is Transformation of data into knowledge, changing the form of knowledge representation, deriving new knowledge from a given knowledge (23).

Steps: Knowledge processing consists of the following steps: Information storing, information retrieving, and information transferring (21).

Key point: Knowledge processing is known as the most important factor affecting economic and social sustainability, Derive value from knowledge processing (23).

\section{Knowledge filtering attributes}

Context: Knowledge filtering can be used to facilitate assimilation. Filtering tries to get the right knowledge to the right person at the right time) 24).

Purpose: Filtering is a tool to help people find the most valuable information so that the limited time spent on reading/listening/viewing can be spent on the most interesting and valuable documents. Filters are also used to organize and structure information (25).

Steps: Knowledge filtering consists of the following steps: Evaluate documents, and puts documents, which are interesting into its structured information database) 25).

Method: The knowledge filtering method is Manual filtering by people, using intelligent agents (24).

Main actors: Computer-based Approaches, publishers, editors, journalists (25).

\section{Knowledge synthesis attributes}

Context: Knowledge synthesis is the contextualization and integration of research findings of individual research studies within the larger body of knowledge on the topic (26).

Purpose: Most syntheses are conducted either for the purpose of knowledge support or for decision support (27).

Steps: Knowledge synthesis consists of the following steps: Stating the objectives of the research, Defining eligibility criteria for studies to be included, Identifying (all) potentially eligible studies, Applying eligibility criteria, Assembling the complete data set feasible including data extraction, quality appraisal of included studies, Analyzing this data set, and Preparing a structured report $(28,29)$.

Method: Knowledge synthesis methods are Systematic review, Realist syntheses, Narrative syntheses, Meta-analyses, Meta-syntheses, Practice guidelines, Consensus conference, or expert panel (30).

Key point: A synthesis must be reproducible and transparent in its methods (26).

\section{Knowledge integration attributes}

Context: The integration of knowledge is the process of incorporating new information into a body of existing knowledge (31).

Purpose: The purpose of knowledge integration is to determine how new and existing knowledge interacts and how existing knowledge should be modified to accommodate the new information (31).

Steps: Knowledge integration consists of the following steps: Dynamic process of linking, connecting, distinguishing, organizing, and structuring ideas about scientific phenomena (32).

\section{Knowledge refinement attributes}

Context: The knowledge refinement process is implemented as part of an organization's knowledge management efforts (33).

Purpose: The purpose of knowledge refinement is to optimize content quality $(33,34)$.

Steps: Knowledge refinement refers to the process of evaluating, analyzing and optimizing the knowledge object to be stored in a repository $(35,36)$

Key point: Knowledge refinement effectiveness is defined as the degree to which the refinement process produces quality knowledge (37). Knowledge refinement process should positively enhance the quality of refined knowledge (37).

\section{Knowledge customization attributes}

Context: Product customization is becoming an increasingly important strategic initiative in knowledge management. Product customization impacts the knowledge management processes of knowledge acquisition, sharing, and transfer (38).

Purpose: The purpose of customization is configuring a product or service to a buyer's specifications (39). The relationships among sales, $R \& D$, and production functions have to strengthen and the KM system has to support such a need (38).

Steps: Knowledge customization consists of the following steps: Collecting information about the customer, choosing options and/or creating new content, deliberately tailors content (40).

Key point: Customization emphasizes the user's role in specifying content; customization is a highly user-driven process of tailoring (41).

\section{Knowledge transfer attributes}

Context: The transfer of knowledge in the broadest sense refers to the flow of knowledge between and within organizations (42).

Purpose: The purpose of knowledge transfer is: decisionmaking, changing individual or organizational behavior, developing policies, problem-solving (43).

Perspectives about Knowledge Transfer: Health perspective, educational perspective, management perspective.

Health perspective: Use of scientific research findings to improve professional performance (44).

Educational perspective: Using generated knowledge in 
a specific context for another context (45).

Management perspective: utilization of the new knowledge for organizational behaviors (46).

Form: Knowledge transfer can be done in the form of formal and informal, planned, and unplanned (46). Planned and unplanned: Knowledge transfer as a process where knowledge is transmitted from one person to another in the form of planned or natural (47).

Formal and informal: Knowledge transfer as an informal way through networks and social interactions in the workplace or formal way in an organization $(47,48)$

Level: Knowledge transfer is a macro process, at the organizational level (42).

Steps: Knowledge transfer consists of the following steps: SECI: Socialization, Externalization, Combination, And Internalization (49).

Areas: Knowledge transfer areas include: Transfer of research findings (50). Technology transfer (51). Transfer of learning, Organizational transfer. (45).

Key point: The concept of knowledge transfer is at the macro level, where knowledge is spreading across sectors, units, or subsets of an organization (42).

\section{Knowledge sharing attributes}

Context: Knowledge sharing is an activity that involves transferring or disseminating knowledge from a person, group, or organization to another.

Purpose: The purpose of knowledge sharing is discovering tools for accessing knowledge inside and outside of organizations with a view to creating more effective management and organizational system (52).

Level: Knowledge sharing can be At the Individual level and micro (53). Among researchers, policymakers, service providers, stakeholders (54).

Activities: Sharing of knowledge is entirely conscious, with a person's desire, without any obligation (53).

Place for sharing Sharing of knowledge occurs at Conferences, social media, Media relation, Scholarly collaboration networks, Journal publication (55)

Direction: It is a Mono directional process: A person's knowledge transforms into a form that can be understood, absorbed, and used by others. Bidirectional: Share information, ideas, suggestions and related organizational expertise with each other (56).

Key point: Common purpose and shared experiences between individuals, and Communication with others are taking place (56).

\section{Knowledge exchange attributes}

Context: In the exchange of knowledge, collaborative problem solving between researchers and decision-makers takes place (54).

Purpose: The exchange of knowledge is to increase the effectiveness of networks and teams in complex environments (54). The exchange of knowledge to create new knowledge (57).

Form: Knowledge exchange is an active process: Researchers make knowledge available to users, and users also transfer knowledge to researchers. It Includes knowledge sharing (what employees give to others) and knowledge search (employees are seeking knowledge from others). (57).

Direction: There are bidirectional relations between researchers or knowledge producers and users.)58).

Key point: The interactions between researchers and decision-makers take place (57).

\section{Knowledge dissemination attributes}

Means for dissemination: Knowledge can be disseminated through articles, journals, conference lectures and other outputs (59).

The type of dissemination: Dissemination of knowledge is in the form of Knowledge, interventions and existing or recent methods (59)

Direction: It is mono-directional, from the top to the bottom and from the expert (59).

Form: Knowledge dissemination is a planned process (59).

\section{Knowledge publication attribute}

Context: One of the major academic duties to share their findings, and to interact with their peers and the general populace, via literal publication (60)

Purpose: The purpose of the publication is the Makingpublic of new knowledge (60).

Steps: Knowledge publication includes the following steps: Find the right journal, prepare the paper, and submit the paper (55).

Form: The publication of knowledge is in the form of Letter, rapid or short communications, Review papers, Full articles, Research elements (data, software, methods, Citable articles, in brief) (55)

Key point: The publication is related to academic journals (55).

\section{Knowledge Brokering}

\section{Knowledge brokering attributes}

Context: Knowledge brokering is one of the human forces behind knowledge transfer. It is a dynamic activity that goes well beyond the standard notion of transfer as a collection of activities that helps move information from a source to a recipient (61).

Purpose: Brokering focuses on identifying and bringing together people interested in an issue, people who can help each other develop evidence-based solutions. It helps build relationships and networks for sharing existing research and ideas and stimulating new work." (62). Knowledge brokering encompasses a wide range of processes and practices that aim at establishing relationships and facilitating effective knowledge sharing and exchange (61).

Form: Knowledge brokering takes place as either formal or informal activities (61).

Type: Types of knowledge brokers are: Information Intermediary (Help Access to knowledge), Knowledge Intermediary (Help Understand and apply the knowledge), Knowledge Brokering (Help use of knowledge in decision making), Innovation Brokering (Changing Context). (61)

Activities: Knowledge brokering activities are: uncovering the needs, ideas, activities, and processes of different 
knowledge environments in order to identify the best research, practices and tools that research partners need to capture, transfer, exchange and collaborate around knowledge (61).

Key point: It engages with obstacles that block the transfer of research into practice (61).

Knowledge storing: Knowledge assimilation, knowledge package, knowledge indexing, knowledge documentation.

\section{Knowledge storage attributes}

Context: Knowledge can be viewed as an item to be stored for future usage (34).

Purpose: Knowledge storage is In order to facilitate the assimilation of knowledge (63).

Type: Knowledge is stored in the form of individual and organizational knowledge, soft or hardstyle recording and retention $(49,64)$

Form: Knowledge store as the form of documents, rules, cases, and diagrams (65)

Method: Technical infrastructure such as modern informational hardware and software, human processes are necessary for storing knowledge (49).

Steps: Knowledge storage steps are: identify the knowledge in an organization, convert the identified knowledge to code, and index the identified knowledge for later retrieval $(49,64)$.

\section{Knowledge assimilation attributes}

Context: A critical aspect of knowledge management is that of assimilation $(66,67)$.

Purpose: 1 . To take in and incorporate as one's own; absorb 2 . To bring into conformity with the customs, attitudes, etc. of a group 3. To convert to substances suitable for incorporation.

Steps: Knowledge assimilation steps are: Storage, massaged, organized, integrate, filtered, navigate $(66,67)$.

Key point: Knowledge can be captured or created, but until it is assimilated it is not likely to receive extensive use (64).

\section{Knowledge package attributes}

Purposes: The purpose of the knowledge package is culling, cleaning and polishing, structuring, formatting, and/or indexing documents against a classification scheme (68).

Activities: Knowledge package activities include Authoring knowledge content, codifying knowledge into "knowledge objects" by adding context, developing local knowledge into "boundary objects" by deleting context, filtering and pruning content, and developing classification schemes (68).

\section{Knowledge indexing attributes}

Context: Knowledge index is to provide a summary about subject content; Indexing activity should be done as a pre analyzing process (69).

Purpose: The purpose of indexing is: organizing the Information in order to effectively use of information (70).

Steps: Knowledge index steps are: Review of documentation and establishment of subject matter, identify the core concept in documents, Referencing selected concepts by the terms of the indexing language (71).

Main actors: Librarian and intermediaries are the main actors for indexing of knowledge (71).

\section{Knowledge documentation attributes}

Context: Preservation and documentation are ways to ensure the future existence of indigenous knowledge, which today is under threat of extinction (72). Facilitating re $\neg$ trieval knowledge is to take place from an organized data set (WIPO, 2016).

Purpose: The aim of documentation is to ensure the maintenance, use, and development of knowledge by present and future generations of peoples and communities (73).

Steps: Knowledge documentation steps are Knowledge identification, Knowledge fixation, and Knowledge classification (73).

Methods: The methods for documentation are Paper files, digital databases, archives, or libraries (73).

Main actors: Librarian and information professionals are the main actors for knowledge documentation (74).

Knowledge transfer: Knowledge sharing, knowledge exchange, knowledge dissemination, knowledge publication.

Knowledge capitalization: Knowledge commercialization, knowledge valorization.

\section{Knowledge capitalization attributes}

Context: Knowledge capitalization is the most important part of KM (75).

Purpose: It aims at building organizational memories that represent several views on expertise or activity (75.)

Activities: Capitalization is the process by which members of the community can identify, locate, model, store, access, use/reuse, share, update, and know-how to communicate the knowledge of the community (75).

Steps: Knowledge capitalization steps are: Knowledge extraction and formalization, Knowledge sharing, Knowledge reuse and appropriation, Memory evolution (75).

Form: Knowledge capitalization happens in the form of: Knowledge locate (identifying, localizing, characterizing, mapping, estimating, prioritizing), knowledge preserve (acquiring, modeling, formalizing, conserving), knowledge enhanced (accessing, disseminating, sharing, using more effectively, combining, and creating), knowledge actualized (appraising, updating, standardizing, enriching, knowledge managed (elaborate a vision: promote, inform, train, facilitate, organize, coordinate, encourage, motivate, measure, and follow up) (76).

\section{Knowledge commercialization attributes}

Context: Commercialization of knowledge is the Third mission of the university, Transfer of knowledge to industry (77).

Purpose: The purpose of commercialization is: Decrease independency to the public sector, Make commercial profit (78). 
Direction: At the commercialization level Corporation between education and industry, dynamic improvement of production, and the economy system is taking place (78).

Steps: Knowledge commercialization steps include flowing: Idea generation, Idea evaluation, Idea development, Commercial analysis of the product, Market assessing, Commercialization (79).

Key point: Commercialization is not a linear process; it is a complex process (79).

\section{Knowledge valorization attributes}

Context: Valorization is a word of French origin translated as a "surplus value". Valorization was framed in the context of the discourse of academic capitalism (80).

Purpose: The purpose of valorization is to transfer knowledge from one part to another for economic benefit" (81).

Path: The process of knowledge valorization is a long route that starts at universities (81). Valorization not only contributes to the availability of the results of academic research beyond academia but also involves the co-production of knowledge by academics and representatives of business (80).

Types: Types of valorization are societal (social) and economic (81).

Main actors: "Valorization is a cooperation between higher education institutions, government, and business players to agree on targeted investments in a number of key areas of regional innovation" (82).

Steps: Knowledge valorization steps are: Knowledge acquisition; amassing the relevant internal and external information required for the transfer of knowledge is collected and quickly deploying this information to its potential users, Knowledge processing; assess the market value of the relevant research and package the knowledge with market potential for business requirements, Knowledge dissemination; delivering of the knowledge package to business and assisting in the technology deployment (83).

Areas: Knowledge valorization areas include: education, Cooperation, contract research, R\&D cooperation, and knowledge, and technology transfer, "entrepreneurship, "the production of successful high-tech start-ups" (84).

Key point: Knowledge-Economy Index which takes into account whether the environment is conducive for knowledge to be used effectively for economic development and Knowledge Index which measures a country's ability to generate, adapt and diffuse knowledge (52). Valorization is broader than commercialization that is focused primarily on making a commercial profit (80).

Knowledge utilization: Knowledge adoption, knowledge adaptation, knowledge reuse.

\section{Knowledge adoption attributes}

Context: The adoption of knowledge is carried out in the field of innovation (46).

Purpose: Adoption is taking place in order to decision making about accept or refuse of innovation (46).

Steps: Knowledge adoption steps include: awareness about new knowledge, attitude formation, and decision about accept or refuse of innovation or new knowledge, implement a new idea or confirm accepted decision (46).

Key point: User motivation for use or rejection, resistance rate about new knowledge, consistency to the policy is determining factors in the knowledge adoption process (85).

\section{Knowledge adaptation attributes}

Context: The adaptation of knowledge is related to the results of the research, and this step is critical to the success of the knowledge transfer process $(86,87)$.

Purpose: The goal is to make the results accessible and understandable by the users $(86,87)$.

Key point: This step affects the user's decision to accept the knowledge generated by the researchers. Also, the availability of research results does not necessarily guarantee acceptance and use by users. Many authors have argued that the form of presentation of research results can be a motivation or obstacle to accepting knowledge in the educational community (87).

\section{Knowledge reuse attributes}

Context: It is a central issue for companies in order to avoid reinventing the wheel over and over again (89). The effective reuse of knowledge is arguably a more frequent organizational concern and one that is clearly related to organizational effectiveness (89).

Purpose: Knowledge reuse is taking place for sharing best practices or helping others solve common technical problems (88).

Steps: Knowledge reuse steps include: Capturing or documenting knowledge, packaging knowledge for reuse, Distributing or disseminating knowledge (providing people with access to it), and Reusing knowledge (35).

Activities: Knowledge reuse activities are followings: recall (that information has been stored, in what location, under what index or classification scheme) and recognition (that the information meets the users' needs), as well as actually applying the knowledge (90).

Agent: There are three major roles in the knowledge reuse process: knowledge producer-the originator and documenter of knowledge, who records explicit knowledge or makes tacit knowledge explicit, knowledge intermediarywho prepares knowledge for reuse by eliciting it, indexing it, summarizing it, sanitizing it, packaging it, and who performs various roles in dissemination and facilitation, and knowledge consumer - the knowledge reuser, who retrieves the knowledge content and applies it in some way (91).

Key point: Successful knowledge transfer or reuse requires a complete solution. It is not just a matter of providing access to information technology and repositories. It also means careful attention to the design of incentives for contributing to and using repositories and to the roles of intermediaries to develop and maintain repositories and to facilitate the process of reuse (89).

\section{Knowledge translation attributes}

Context: The translation is the process of putting research findings and the products of research into the hands 
of key audiences. It is the art of weaving together processes of research and practice (92).

Purpose: Knowledge Translation is impact-oriented- the overarching goal of KT is to improve systems, practices, and ultimately lead to better outcomes (93).

Activity: Knowledge Translation includes multiple activities- Researchers need to go beyond mere dissemination and publication of results to multiple engagements to effect knowledge uptake (93).

Direction: Knowledge translation is a nonlinear processit is also a complex process with multiple players, it also needs multidirectional communications (93).

Agent: Knowledge translation is an interactive processthe interactions between knowledge producers and knowledge users should be continuous. KT requires ongoing collaborations among relevant parties- collaboration, relationships, and trust among parties (92).

Steps: Knowledge translation includes all steps between the creation of new knowledge and its application (93).

Key point: It emphasizes the use of research-generated knowledge (93).

\section{Knowledge management attributes}

Context: Knowledge management is the process of transferring information and intellectual assets to a stable value. And it is related to making knowledge suitable for the correct processor, such as a human being or a computer, at the right time and at the right cost (94).

Purpose: The purpose of knowledge management is to create the knowledge that can be used by more than one person, for example, for the organization as a whole, or sharing knowledge between its members (94). Help to promote the use and sharing of data and information in decision making (95).

Activity: Knowledge management involves planning, organizing, and controlling individuals, processes, and systems to ensure that knowledge capital is promoted and applied effectively (33).

Type: Knowledge management has multidisciplinary nature, which includes: organizational science, cognitive science, information technology, linguistics, technical writing, ethnology and sociology, teaching, Communication studies, collaborative technologies such as computer-based collaborative activities, intranets, extranets, portals, and other network technologies (96).

Path: Under the knowledge management, the information becomes applicable to the knowledge and is applicable to the people who can use it (97).

Steps: Knowledge management steps involve: obtaining, organizing, managing, and disseminating knowledge in an organization in order to perform tasks faster, reuse best practices, and reduce costs twice (49). The process of finding, selecting, organizing, importing, and providing information in order to help raise the understanding of employees in a particular area (98).

Form: Knowledge management has two main aspects: knowledge as an obvious concern that reflects on organizational strategies, policies, and practices. On the other hand, it takes into account the relationships between intellectual capital (both apparently recorded and implicit in the form of personal knowledge) and Positive business results (99).

\section{Discussion}

Studies have examined one or a few concepts in the field of knowledge management. Through this study, we were able to investigate all of the concepts related to knowledge management as far as possible. By criticizing and comparing the evidence and definitions relating to them, based on semantic proximity, we divided them into related categories and, clarify the boundary among them. We realized that many concepts had not found their appropriate place in the $\mathrm{KM}$ process, and there are no proper definitions of them. Therefore, it is necessary to redefine some of the concepts and the correct placement in the structure and operation of knowledge management. We can use the results of this study as the basis and the first step in developing a comprehensive model that includes all the concepts related to knowledge management and for determining the relationship among them and with other educational development concepts.

\section{Conclusion}

This study aimed to clarify the concepts in the knowledge management area. Through critically reviewing the literature in this field, we were able to identify the concepts and realize their attributes. Therefore, we came to a new interpretation of the concepts. At the end of the study, we concluded that some of the concepts have not been properly defined and are not properly located in the knowledge management field, and their application is uncertain. Regarding the identified gaps, there is a need to comprehensively study that consider all of these in the direction of knowledge management, show their application in a comprehensive model and, if necessary, redefined them, such as study can complement our work.

\section{Acknowledgment}

This article is a part of the dissertation entitled Educational Development with Approach on Knowledge Management. The authors would like to appreciate everyone who assisted them in this research.

\section{Conflict of Interests}

The authors declare that they have no competing interests.

\section{References}

1. Drucker P. The social age of transformation. Atlantic Monthly. 1994 Available from: http://www.theatlantic.com/ politics/ecbig/soctrans.

2. Bart S. Heeding the sage of the knowledge age. CRM Magazine. 2000. Available from: http://www.destinationcrm.com/ articles/default. Article ID $=832$.

3. Hsia TL, Lin LM, Wu JH, Tsai HT. Framework for designing nursing knowledge management systems. Interdiscip J Inf Knowl Manag. 2006;1(1):13-22.

4. Prusak 1. Knowledge and trainning: the missingconnection. Newyourk: Mc Graw-Hill 2001.

5. Laal M. Knowledge management in higher education. Procedia Comput Sci. 2011;3:544-9.

6. Pircher R, Pausits A. Information and knowledge management at higher education institutions. Manag Inf Syst. 2011; 6(2):8-16.

7. McCarthy AF. Knowledge management: evaluating strategies and processes used in higher education. [Dissertation]: Nova Southeastern 
University, 2006.

8. Metaxiotis K, Psarras J. Applying knowledge management in higher education: the creation of a learning organization. J Inf Knowl Manag. 2003;2(4):353-9.

9. Carnwell R, Daly W. Strategies for the construction of a critical review of the literature. Nurse Educ Pract. 2001;1(2):57-63.

10.Schwartz DG, Brasethvik T. On Knowledge Management in the Internet Age. In D.G. Schwartz, M. Divitini, and T. Brasethvik (Eds.) Internet-Based Organizational Memory and Knowledge Management, Hershey: Idea Group Publishing, 2000; 1-23.

11.Holsapple CW, Jones KG. Exploring Primary Activities of the Knowledge Chain. Knowl Process Manag. 2004;11(3):155-174.

12. Holsapple CW, Singh M. The Knowledge Chain. In Proceeding of the Annual Conference of the Southern Association on Information Systems, Atlanta, Georgia. 2000.

13.Wagner WP, Zubey ML. "Knowledge acquisition for marketing expert systems based upon marketing problem domain characteristics". Mark. Intell Plan. 2005;23(4):403- 416.

14. Peteraf M. The Cornerstones of Competitive Advantage: A Resourcebased View. Strateg. Manag. J. 1993;14:179-191.

15. Styhre A, Roth J, Ingelgard A. Care of the other: knowledge-creation through care in professional teams. Scand J Manag. 2002;18(4):503.

16.Nizar B; Saliha Z; Othman I; Yan; Réjean C. How to improve knowledge transfer strategies and practices in education? Answers from a systematic literature review. Res High Educ. 2010;7:1-21.

17.Phan PH, Peridis T. Knowledge creation in strategic alliances: Another look at organizational learning. Asia-Pac J Manag Res Innov. 2000;17(2):201-222.

18. Scardamalia, M., \& Bereiter, C. Higher levels of agency for children in knowledge building: A challenge for the design of new knowledge media. J Learn Sci. 1991a;1(1):37-68.

19. Scardamalia, M., \& Bereiter, C. Knowledge building. In J. W. Guthrie (Ed.), Encyclopedia of education. New York, NY: Macmillan Reference. 2003, (2nd ed.Vol. 17, pp. 1370-1373).

20.Bell P, Hoadley C. M, \& Linn, M C. Design-based research in education. In M. C. In Linn E, A Davis, \& P Bell (Eds.), Internet environments for science education Mahwah, NJ: Erlbaum. 2004;7385 .

21. Abhary K, Adriansen H K, Begovac F , Djukic D, Qin B, Spuzi S, et al .Some basic aspects of knowledge. Procedia Soc Behav Sci. 2009; 1:1753-1758.

22. Burgin M. Knowledge Processing as Structure Transformation. Presented at the IS4SI 2017 Summit DIGITALISATION FOR A SUSTAINABLE SOCIETY, Gothenburg, Sweden, 12-16 June 2017. Published: 9 June 2017.

23. Burgin M. Theory of Knowledge: Structures and Processes. World Scientific: New York, NY, USA; London, UK; Singapore. 2016.

24. Daniel E, O'Leary. Management of reengineering knowledge: AIbased approaches. Intell Syst Account Fin Manag. 2000;9(2):107-118.

25. Jacob Palme, Information Filtering .Department of Computer and Systems Sciences Stockholm University and KTH Technical University Skeppargatan $73 . \quad$ Available from: http://www.dsv.su.se/ jpalme/select/information-filtering.html

26. Canadian Institutes of Health Research. Knowledge translation. 2008. Available from: URL: http://www.cihr.ca/e/29418.html.

27. Mays N, Pope C, Popay J. Systematically reviewing qualitative and quantitative evidence to inform management and policy-making in the health field. J Health Serv Res Policy. 2005;10(1): 6-20.

28.Chalmers I. Trying to Do More Good than Harm in Policy and Practice: The Role of Rigorous, Transparent, Up-to-Date Evaluations. Ann Am Acad Political Soc Sci. 2003;589(1): 22-40.

29. Pope C, Mays N, Popay J. Synthesizing Qualitative and Quantitative Health Research. a guide tomethods. Open University Press. 2007.

30.Cochrane Collaboration. Glossary of Terms in the Cochrane Collaboration. Oxford: The Cochrane Collaboration. 2005.

31.Kenneth S. Murray KI. A Tool for Knowledge Integration. 1996. From: AAAI-96 Proceedings. Copyright (C) 1996. AAAI (www.aaai.org). All rights reserved.

32. Clark, D. B. Analyzing Student Knowledge Interaction: Theories or pieces? In Proceedings of the National Association of Research in Science Teaching Conference [CD-ROM]. 2003. Philadelphia: National Association for Research in Science Teaching.

33. Cho K, Chung T.R, King W.R, Schunn, C. "Creating a peer-based computer-supported knowledge refinement process," Commun ACM. 2008;51(3):83-88

34. Zack M.H. "Managing codified knowledge," MIT Sloan Manag. Rev. 1999;40(4):45-58.

35. Alavi M. "Managing organizational knowledge" in: Framing the Domains of IT Management: Projecting the Future.Through the Past, R.W. Zumd (ed.), Pinnaflex Educational Resources, Cincinnati, Ohio. 2000.

36. Markus M.L, Majchrzak A, Gasser L. "A design theory for systems that support emergent knowledge processes". Mis Q. 2002;26(3):179212.

37. Hackman R. "The design of work teams," in: Handbook of Organizational Behavior, J. Lorsch (ed.), Prentice Hall., Englewood Cliffs, NJ. 1987.

38. Lorenzo C, Marta F, Fabio N, Pietro R .How customization and new product introduction rate impact knowledge management practices. Department of Electrical, Managerial and Mechanical Engineering, University of Udine.

39. Serino C. M, Furner C.P, \& Smatt C. making it personal: How personalization affects trust over time. Paper presented at the 38th Hawaii International Conference on Systems Sciences. 2005.

40. Shyam Sundar S. Personalization versus Customization: The Importance of Agency, Privacy, and Power Usage. Hum Commun Res. 2010;36(3):298-322

41. Nielsen J. Personalization is over-rated. 1998. Retrieved from http:// www.useit.com/alertbox/981004.html.

42. Szulanski G. exploring internal stickiness: impediments to the transfer of best practice within the firm. Strateg Manag J. 1996;17(S2):27-43.

43. Landry R, Amara N, and Lamari M. Utilization of social science research knowledge in Canada. Res Policy. 2001;30(2): 333-349.

44. Gupta S, Sharma S.L, and Dutta K. Using Knowledge Mapping to Support Knowledge Management in Health Organizations. 2006. http://library.igcar.gov.in/readit2007/conpro/s2/S2 5.pdf.

45. Presseau A, and Frenay M. Le développement des compétences professionnelles: quelles jonctions possibles entre l'articulation théorie/pratique ET le transfert? In Pressea Annie ET Frenay Mariane (Eds). Le transfert des apprentissages; comprendre pour mieux intervenir. Ste-Foy, les Presses de l'Université Laval.2004.

46. Roy M, Guindon J.C, Fortier L. Transfert de connaissances- revue de littérature ET proposition d'un modèle. Études ET recherches, IRSST. 1995; 099. 53 p. http://www.irsst.qc.ca/fr/ publicationirsst 460.html

47. Argote L, Ingram PK. Knowledge Transfer: A Basis for Competitive Advantage in Firms. Organ Behav Hum Decis Process. 2000;82(1):150-169.

48. Lahti R. K, Darr E. D, and Krebs V. E. Developing the productivity of a dynamic workforce: The impact of informal knowledge transfer. J Organ Excel. 2002;21(2):13-21.

49. Nonaka I, and Takeuchi K. The Knowledge Creating Company: How Japanese Companies Create the Dynamics of Innovation, Oxford University Press. 1995.

50. Lavis J.N, Robertson D, Woodeside J. M, McLeod C. B, and Abelson J.The Knowledge Transfer Study Group. How Can Research Organizations More Effectively Transfer Research Knowledge to Decision Makers? Milbank Q. 2003;81(2):221-248.

51.Argabright G. C. Using technology transfer to improve safety and health. Prof Saf. 1999;44(9):28-33.

52.Cummings, J. Knowledge Sharing: A Review of the Literature. Washington, D.C. The World Bank Operations Evaluation Department. 2003.

53.Laurent T, and Gabriel V.B. Knowledge management through the development of knowledge repositories: towards work degradation. New Technol Work Employ. 2015;30(2).158-172.

54.Tsui L, Chapman S, Schnirer L, and Stewart S. A Handbook on Knowledge Sharing: Strategies and Recommendations for Researchers, Policy Makers and Service Providers. 2006.

55.Elsevier.com/authors-update, understanding the publishing process how to publish in scholarly journals. 2018.

56. Bartol K.M, Srivastava A. Encouraging Knowledge Sharing. The Role of Organizational Reward Systems. J Leadersh Organ Stud. 2002;9(1):64-76.

57.Bart van den Hooff, Jan A. Knowledge sharing in context: the influence of organizational commitment, communication climate and CMC use on knowledge sharing. J Knowl Manag. 2004;8(6):117-130.

58. Cheikh F, Monique L, Lise D. Guide to Knowledge Transfer. Designed for Researchers in Occupational Health and Safety. 2008.

59. Neuhauser L. Creating and implementing large-scale parenting education programs: bridging research, decision making and practice. 
In Michaux A, Sanson A, and Bammer G. (Eds). Bridging the 'knowdo' Gap: Knowledge Brokering to Improve Child Wellbeing. Canberra: ANU Press. 2010; 91-109.

60. Fornäs J, Martin F, Eva H. Wirtén \& Naomi Stead: "Introduction: Publishing for Public Knoowledge", Culture Unbound, Published by Linköping University. Electronic Press. 2015. Available from: http://www.cultureunbound.ep.liu.se.

61. Cummings R. Building knowledge futures for cerebral palsy: examples from The Spastic Centre. In Michaux, A., Sanson, A. and Bammer, G. (Eds), Bridging the 'know-do' Gap: Knowledge Brokering to Improve Child Wellbeing.Canberra: ANU Press. 2010:37-55.

62. Canadian Health Services Research Report. The Theory and Practice of Knowledge Brokering in Canada's Health System. 2003. Available from: http://www.chsrf.ca/migrated/pdf/Theory_and_Practice_e.pdf.

63. Alavi M, Leidner D.E. Knowledge Management and Knowledge Management Systems: Conceptual Foundations and Research Issues. MIS Quarterly. 2001; 25: 107-136. http://dx.doi.org/10.2307/3250961

64. Armstrong M. Handbook of Human Resource Management Practice). (11th Ed.).London and Philadelphia: Kogan Page Ltd. 2009.

65. Daniel E, O'Leary. Technologies for Knowledge Assimilation Marshall School of Business, University of Southern California, Los Angeles, 2000. CA 90089-0441 oleary@usc.edu.

66. O'Leary DE. "Using AI in Knowledge Management: Knowledge Bases and Ontologies," IEEE Intelligent Systems.1998c, 34-39.

67. O'Leary DE. "Reengineering and Knowledge Management," in D. Fensel and R. Studer (eds) Lecture Notes in Computer Science, Springer. 1999:1-12.

68. Roth G, Kleiner A. Developing organizational memory through learning histories. Organ Dyn. 1998;27(2):43-59.

69. Cleveland Donald B, Cleveland Ana D. Introduction to indexing and abstracting. 3rd ed. Englewood: Libraries Unlimited. 2001.

70. Bertrand, Annick, Cellier, JeanMarie, Giroux, Luc. Expertise and strategies for the identification of the main ideas in document indexing. Appl Cogn Psychol.1996; 10: 419- 433.

71. Jens-Erik M. "Semiotics and indexing: An analysis of the subject indexing process". J Doc. 2001;51(5)

72. Sithole, J. The challenges faced by African libraries and information centres in documenting and preserving indigenous knowledge. IFLA. 2007;33(2):117-123.

73. World Intellectual Property Organization 34, chemin des Colombettes. 2016. P.O. Box. 18 CH-1211 Geneva 20 Switzerland.

74. Ngulube P. Managing and preserving indigenous knowledge in the knowledge management era: challenges and opportunities for information professionals. Inf Dev. 2002;18(2):95-100.

75. Grundstein M, Rosenthal-Sabroux, C. GAMETH, A Process Modeling Approach to Identify and Locate Crucial Knowledge, In Proceedings the 12th World Multi-Conference on Systemics, Cybernetics and Informatics KGCM. 2008;49-54.

76. Grundstein M, Rosenthal-Sabroux C, and Pachulski A. Reinforcing decision aid by capitalizing on company's knowledge: Future prospects. Eur J Oper Res. 2003;145(2): 256-272.

77. Taylor P, Braddock R. Commercialization and the function of the University. Int J Learn. 2006;12:1-10.

78. Etzkowitz, Henry. Research groups as quasi- firms: The invention of the entrepreneurial university, Research policy. 2003.

79.Pellikka J. and Virtanen M. 'The problems of commercialisation in small technology-based. Int J Entrep Innov Manag. 2009;9(3):267-284.

80.Benneworth P, Jongbloed B. Who matters to university? A stakeholder perspective on humanities, arts and social sciences valorization. High Educ. 2010;59(5):567-588.

81.Andriessen D. Value, valuation, and valorization. 2005. Available from: www.inovacao.usp.br/ images/pdf/.

82.University Amsterdam "University Amsterdam strategic plan. 20112015". 2010. available from: www.vu.nl/en/about-vuamsterdam/mission-and-profile/strategic-plan/index.asp.

83. Ala S, Vilarinho P, PORTUGAL C. Knowledge valorization and the European Paradox: a case study. Recent Advances in Applied Economics: 6th International Conference on Applied Economics, Business and Development (AEBD'14). Eds. Mastorakis, Nikos E., Panos M. Pardalos and Michael N. Katehakis. Lisbon: WSEAS Press. 2014.

84. "Wageningen University and Research centre (UR) strategic plan 2011-2014". 2011. available from: www.wageningenur.nl/upload_mm/2/5/.

85. Hemsley-Brown J, and Sharp C. "The use of research to improve professional practice: A systematic review of the literature." Oxf Rev
Educ. 2003;29(4):449-470

86. Kirst, M. W. "Bridging education research and education policymaking." Oxf Rev Educ. 2000;26(3/4):379-391.

87. Love JM. "Knowledge Transfer and Utilization in Education". Rev Res Educ. 1985;12(1):337-386.

88. Davenport TH, Jarvenpaa SL, Beers MC. Improving knowledge work processes. MIT Sloan Manag. Rev. 1996;37(4):53-65.

89.Dixon NM. Common Knowledge: How Companies Thrive By Sharing What They Know? Boston, MA: Harvard Business School Press. 2000.

90. Lansdale, M. The psychology of personal information management. Appl Ergon. 1988;19(1):55-66.

91. Gundry J, Metes G. Team knowledge management: A computermediated approach, working by Wire SM TM. 1996. http://www.knowab.co.uk/wbwteam.html.

92. Lyon R, Warner G. Demystifying knowledge translation for stroke Researchers: A primer on theory and praxis. Halifax, NS: Atlantic Health Promotion Research Centre. 2005

93. Canadian Institutes of Health Research, Annual Report. 2006-2007 .available from: http://www.cihr-irsc.gc.ca/e/34770.html.

94. Firestone J. Enterprise information portals and knowledge management. Boston: Butterworth-Heinemann. 2003.

95. Petrides L, and Nodine T. Knowledge management in education: defining the landscape. The Institute for the Study of Knowledge Management in Education. 2003.

96. Dalkir K. Knowledge Management in Theory and Practice. Boston: Butterworth-Heinemann. 2005.

97. Information Week). Ten Principles for Knowledge Management Success. 2003. Available from: http://whitepapers.informationweek.com.

98.Little T. Understanding Knowledge Management: Developing a Foundation for Future Advising Practices. NACADA Clearinghouse of Academic Advising Resources. 2010. Available from: http://www.nacada.ksu.edu/Resources/Clearinghouse/ViewArticles/Knowledge-management.aspx.

99. Lee H, Choi B. Knowledge management enablers, processes and organizational performance: An integrative view and empirical examination. J Manag Inf Syst. 2003;20(1):179-228. 